\title{
Caracterização anatômica da lâmina foliar de populações de Bromus auleticus Trin. Ex Nees (Poaceae)
}

\author{
Cercí Maria Carneiro* \\ Marta Vanise Bordignon \\ Simone Meredith Scheffer-Basso \\ Miguel Dall'Agnol
}

Instituto de Ciências Biológicas, Universidade de Passo Fundo, Campus I

CEP 99001-970, Passo Fundo, RS, Brasil

*Autora para correspondência

cerci@upf.br

Submetido em 29/12/2007

Aceito para publicação em 11/06/2008

\section{Resumo}

Este trabalho teve como objetivo caracterizar anatomicamente a lâmina foliar de oito populações de Bromus auleticus coletadas no Rio Grande do Sul e denominadas de A5, A6, A7, A8, A17, A23, A26 e A27. Folhas totalmente expandidas foram coletadas de plantas em estádio vegetativo, seccionadas e coradas com fucsina e azul de Alcian. Verificou-se em todas as populações a presença de epiderme uniestratificada, com cutícula lisa e delgada em ambas as faces, tricomas curtos, feixes vasculares de três tamanhos e células com parede lignificada junto aos feixes e no bordo foliar. O número de células buliformes varia de três a cinco, com exceção da população A26, com cinco a oito células. Três populações possuem tricomas longos (A6, A23, A27) e clorênquima em paliçada (A6, A7, A26), cinco exibem sulcos na superfície foliar (A8, A17, A23, A26, A27) e clorênquima homogêneo (A5, A8, A17, A23, A27), duas apresentam amplos espaços intercelulares no mesofilo (A7, A17) e duas, cutícula mais evidente na face abaxial (A7, A8). Essas variações podem refletir diferenças no valor nutritivo das populações e serem exploradas nos trabalhos de melhoramento genético da cevadilha vacariana.

Unitermos: anatomia vegetal, cevadilha, forrageira

\section{Abstract}

Leaf anatomic characterization of populations of Bromus auleticus Trin. Ex Nees (Poaceae). This work was carried out to characterize the leaf anatomy of eight Bromus auleticus populations collected in Rio Grande do Sul, Brazil, and called A5, A6, A8, A17, A23, A26 and A27. Totally expanded leaves were collected from plants in the vegetative stage and were sectioned and stained with basic fuchsine and alcian blue. A single layer of epidermis with a smooth and fine cuticle on both surfaces, short tricomes, vascular bundles in three sizes, and the presence of cells with lignified walls along the bundles and on the leaf edge were observed in all populations. The number of bulliform cells varied from three to five, with the exception of population A25, which ranged from five to eight cells. Three populations presented long tricomes (A6, A23 and A27) and palisade chlorenchyma (A6, A7 and A26), five had grooves on the leaf surface (A8, A17, A23, A26, A27) and homogeneous chlorenchyma (A5, A8, A17, A23, A27), two presented a large intercellular space in the mesofile (A7 and A17), and two showed a more visible cuticle on the abaxial surface (A7 and A8). These variations 
could reflect differences in relation to the nutritive value of the populations and be used in plant breeding programs for the genetic improvement of bromegrass.

Key words: bromegrass, forage plant, plant anatomy

\section{Introdução}

O gênero Bromus pertence à família Poaceae e compreende cerca de sessenta espécies, adaptadas a regiões de climas frios ou com predominância de estações frias durante o crescimento da planta (Carlson e Newell, 1985). No Rio Grande do Sul ocorrem cinco espécies de Bromus L. (Longhi-Wagner, 1987), dentre as quais B. auleticus Trin. Ex Nees, conhecida como cevadilha vacariana. É uma espécie perene, hibernal, com ótimo potencial forrageiro (Barreto e Kappel, 1967) e destacada variabilidade fenotípica, bromatológica e de produção de forragem (Silveira et al., 1997; Scheffer-Basso et al., 2005). Oliveira e Moraes (1993) obtiveram elevados teores de proteína bruta (25\%) e digestibilidade in vitro da matéria seca (73\%) durante o inverno, época em que essa gramínea se encontra em estádio vegetativo. No Uruguai, já foram registrados os cultivares Potrillo e Zarco (Millot, 2001), atestando, portanto, o seu valor forrageiro.

Alguns aspectos anatômicos da cevadilha vacariana foram descritos por Ramos et al. (2002) e Gasser et al. (2002). No entanto, estudos dessa ordem ainda têm sido pouco utilizados nos programas de melhoramento genético de plantas forrageiras. Segundo Buxton e Redfearn (1997), a seleção de plantas para componentes anatômicos é difícil, em razão do intenso trabalho manual requerido e das pequenas alterações nos tipos de células associadas com a melhoria da digestibilidade. No entanto, as características anatômicas de folhas e caules podem ser utilizadas complementarmente como descritores de germoplasma de plantas forrageiras e no melhor entendimento da variabilidade temporal da qualidade nutricional das pastagens. Gasser et al. (2002) relacionaram a anatomia foliar da cevadilha vacariana com a digestibilidade ruminal, concluindo que a espécie apresenta características anatômicas foliares favoráveis a tal processo. Em Bromus inermis, Ehlke e Casler (1985) verificaram estreita base genética para digestibilidade in vitro da matéria seca e anatomia foliar, ao compararem dezoito clones da espécie.
O presente trabalho teve como objetivo descrever a organização estrutural da lâmina foliar de oito populações de cevadilha vacariana, visando fornecer subsídios aos programas de melhoramento genético.

\section{Material e Métodos}

O experimento foi conduzido na Universidade de Passo Fundo, região do Planalto Médio do Rio Grande do Sul, a $28^{\circ} 15^{\prime}$ de latitude sul e $52^{\circ} 24^{\prime}$ de longitude oeste, com altitude de aproximadamente $700 \mathrm{~m}$ acima do nível do mar. O clima pertence à Zona Climática Fundamental Temperada $\mathrm{C}$, do tipo fundamental úmido (f) e variedade subtropical (Cfa) (Moreno, 1961). O solo da área experimental é um latossolo vermelho-escuro distrófico, que apresentou por ocasião da implantação do ensaio as seguintes características químicas: $45 \mathrm{~g} / \mathrm{kg}$ de argila; $\mathrm{pH}$ em água $=5,60 ; \mathrm{pH}$ SMP $=5,70 ; \mathrm{P}=17 \mathrm{mg} / \mathrm{L}$; $\mathrm{K}=141 \mathrm{mg} / \mathrm{L}$ e $2,5 \%$ de matéria orgânica.

A investigação avaliou oito populações de cevadilha vacariana coletadas em municípios do Rio Grande do Sul e identificadas como A5, A6, A23, A26 (Santana do Livramento), A27 (Quaraí), A7 (Uruguaiana), A17 e A8 (Júlio de Castilhos). As plantas foram estabelecidas, mediante mudas, em abril de 2002, em delineamento completamente casualizado, com dez repetições (plantas individuais) distantes $80 \mathrm{~cm}$ entre si.

Folhas completamente expandidas foram coletadas aleatoriamente de plantas em estádio vegetativo, em março de 2003. Após a coleta, foram imediatamente fixadas em FAA 70 por aproximadamente $48 \mathrm{~h}$ e conservadas em etanol $70^{\circ} \mathrm{GL}$ (Johansen, 1940). As secções transversais da lâmina foliar foram feitas à mão livre, coradas mediante a combinação de fucsina e azul de alcian (Luque et al., 1996) e montadas com glicerina $50 \%$. Após a seleção das melhores lâminas foram feitas fotografias em fotomicroscópio Olympus BX50. 


\section{Resultados e Discussão}

Em secção transversal, as folhas da cevadilha exibem epiderme uniestratificada e revestida por cutícula lisa e delgada em ambas as faces, na maioria das populações. Nas populações A7 e A8 a cutícula mostrase mais evidente na face abaxial (Figura 1A-B-C). Gasser et al. (2002) relataram a presença de células epidérmicas com paredes cutinizadas e engrossadas em cevadilha vacariana e que, mediante análise de digestibilidade in situ, apresentaram maior resistência à degradação. Em gramíneas é comum a presença de impregnações nas paredes celulares periclinais externas. Em gramamissioneira (Axonopus sp.), Silva e Alquini (2003) observaram epiderme abaxial com a parede periclinal externa lignificada.
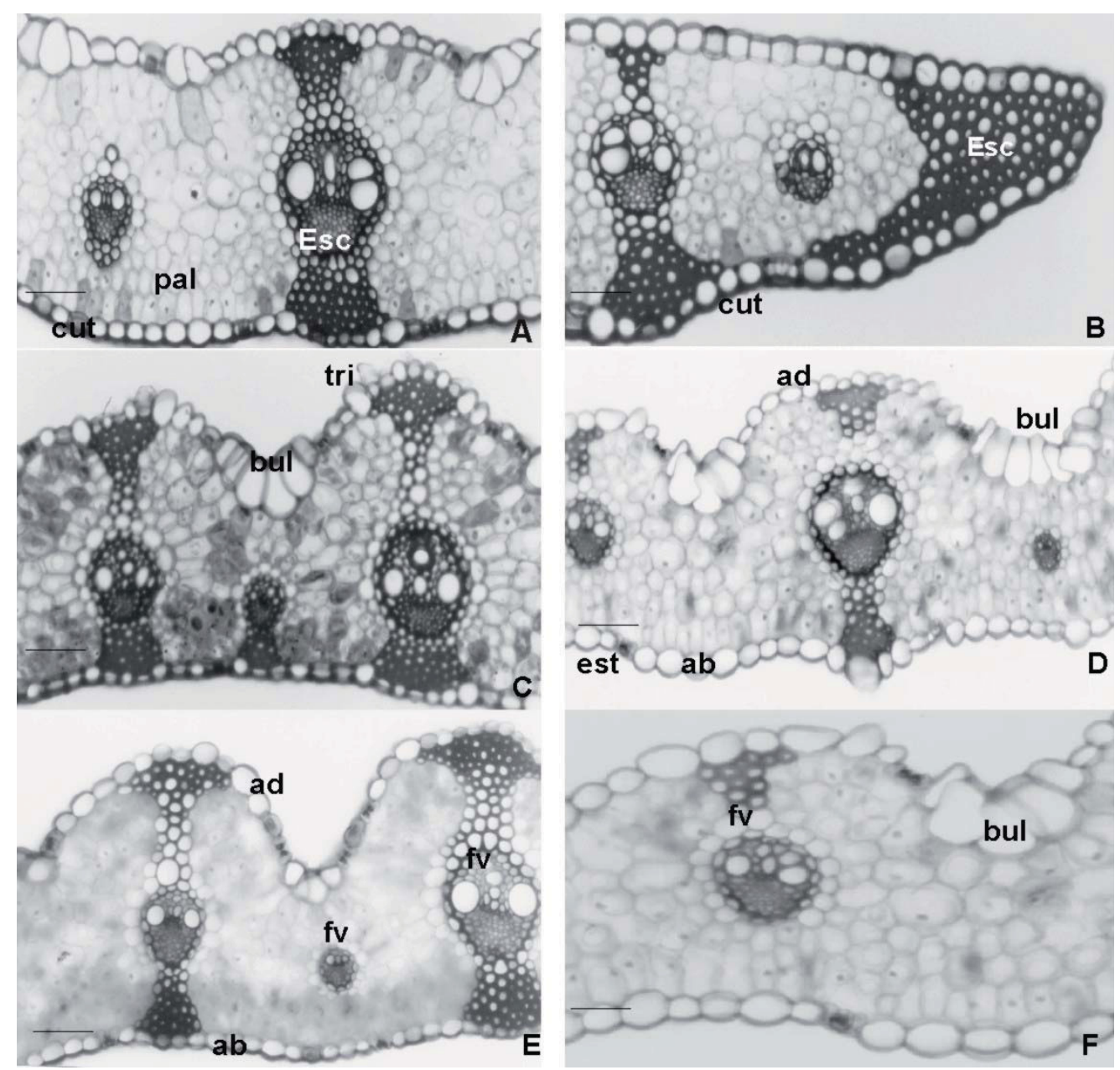

FIGURA 1: Secções transversais da lâmina foliar de populações de Bromus auleticus A-B (A7); C (A8); E (A17); D-F (A26). Células buliformes (bul); cutícula (Cut); epiderme adaxial (ad); epiderme abaxial (ab); esclerênquima (esc); estômato (est); feixe vascular (fv); parênquima paliçádico (pal); tricoma (tri). Barra: $50 \mu \mathrm{m}$.
Segundo Hacker (1981), os benefícios práticos de selecionar genótipos com menores níveis de cutinização dependerão do quanto essa substância inibe a digestão ruminal e dos possíveis efeitos deletérios que poderiam ocasionar, como, por exemplo, aumentar a transpiração, reduzir a produção de forragem e aumentar a susceptibilidade a doenças. Delgado et al. (2002) destacaram que o aumento na digestibilidade de Bromus inermis foi promovido pela redução na concentração de lignina.

A lâmina foliar apresenta complexos estomáticos em ambas as faces (Figura 1F), tal como observada por Ramos et al. (2002) na mesma espécie. Observou-se presença de câmara sub-estomática, formada pelo arranjo diferenciado das células parenquimáticas abaixo dessa estrutura (Figura 2C). A epiderme adaxial apresenta de 
três a cinco células buliformes, mas na população A26 ocorrem até oito dessas células (Figura 1D), sugerindo maior tolerância à deficiência hídrica.

Outros estudos com cevadilha vacariana relataram a presença de três células buliformes (Gasser et al., 2002; Ramos et al., 2002). Essas células estão relacionadas com o enrolamento da folha e com a deficiência hídrica e são caracteristicamente maiores que as células epidérmicas típicas (Mauseth, 1988; Fahn, 1990). Neste estudo, tais células apresentaram paredes delgadas, principalmente as anticlinais (Figura 1D e 2D), concordando com o descrito por Brito e Rodella (2002) em braquiária (Brachiaria sp.).

As folhas das populações A8, A17, A23, A26 e A27 possuem superfície adaxial ondulada, com sulcos na região compreendida entre os feixes vasculares, onde estão localizadas as células buliformes e os complexos estomáticos (Figuras 1C-D-E e 2F), o que não foi observado nas demais populações (Figuras 1A e 2B-E). A presença desses sulcos também foi verificada por Ramos et al. (2002) em cevadilha vacariana. Alvarez et al. (2005), em estudo anatômico das gramíneas do cerrado brasileiro, Loudetiopsis chrysothrix (Nees) Conert e Tristachya leiostachya Nees, observaram estômatos alojados em sulcos na superfície adaxial, diferenças no grau de sinuosidade das paredes das células epidérmicas e paredes celulares de estrutura complexa.

Em todas as populações foram observados, na epiderme de ambas as faces, tricomas tectores unicelulares simples, curtos, pontiagudos e com aspecto silicificado (Figura 1C). Na mesma espécie, Gasser et al. (2002) e Ramos et al. (2002) descreveram essas estruturas como agulhas epidérmicas. As populações A6, A23 e A27 apresentam, também, tricomas longos (Figura 2A). Tais observações, em nível de microscopia fotônica, são importantes para confirmar se as folhas de cevadilha vacariana são realmente glabras ou pilosas, pois, muitas vezes, a olho nú ou com o auxílio do microscópio estereoscópico, tais tricomas não são visíveis. Com as mesmas populações, Scheffer-Basso et al. (2005) caracterizaram as populações A8 e A17 como glabras e as demais, como pilosas. Isso reforça, portanto, a importância dos estudos anatômicos na descrição de germoplasma.
No estudo de Silveira et al. (1997) a pilosidade das folhas foi o melhor marcador genético na discriminação de acessos de cevadilha vacariana. Em B. inermis, Ferdinandez e Coulman (2001) e Traverso (2001) também verificaram variação para tal característica. Oliveira et al. (2001) observaram que populações de cevadilha vacariana que apresentavam pilosidade nas duas faces das folhas o florescimento foi precoce, ao contrário das populações glabras, que foram tardias, sugerindo associação entre a fenologia e a morfologia foliar.

O mesofilo caracteriza-se pela presença de parênquima clorofiliano homogêneo. Porém, nas populações A6, A7 e A26, as células próximas à epiderme são mais alongadas formando um parênquima paliçádico (Figura 1A-D). Ramos et al. (2002) e Gasser et al. (2002) mencionaram para a espécie a existência de espaços amplos entre as células do mesofilo, o que foi também evidenciado nas populações A7 e A17 (Figuras $1 \mathrm{E}$ e 2D), sugerindo maior degradabilidade. As demais populações apresentam espaços reduzidos.

O grau de compactação das células tem relação com o teor de proteína bruta (PB), pois quanto menores os espaços intercelulares, maior o número de células por área e, conseqüentemente, maior quantidade de conteúdo celular. De fato, com as mesmas populações, SchefferBasso et al. (2005) verificaram menor teor de PB na população A17 (16,9\%) em relação às populações A5 (20,5\%) e A6 (19,95\%). Em gramíneas C3, as células são frouxamente arranjadas, apresentando poucos pontos de aderência. Isso permite aos microorganismos ruminais um rápido acesso às paredes celulares, proporcionando elevada taxa de digestão e facilitando a fragmentação pela mastigação (Paciullo, 2002).

$\mathrm{O}$ esclerênquima descontínuo ocorre nas duas faces da lâmina foliar, apresentando-se como grupos sub-epidérmicos correspondentes aos feixes vasculares (Figuras 1A e 2A). A região do bordo foliar exibe grande quantidade de fibras com paredes celulares intensamente lignificadas (Figura 1B). Gasser et al. (2002) relataram para cevadilha vacariana maior porcentagem de esclerênquima quando comparada à Setaria lachnea. Collins e Drolson (1982), ao avaliarem clones de $B$. inermis, selecionados para alta e baixa digestibilidade in 

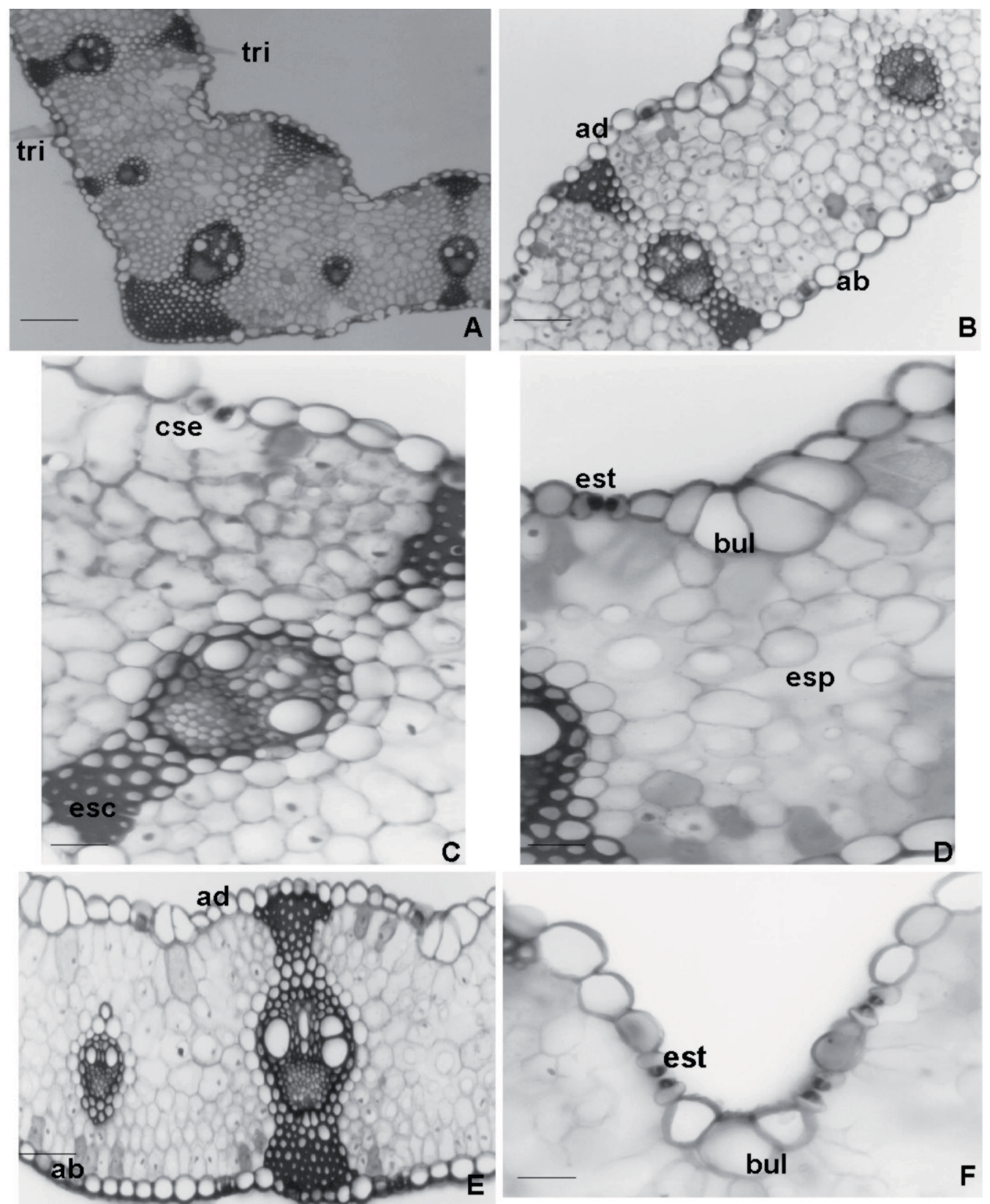

FIGURA 2: Secções transversais da lâmina foliar de populações de Bromus auleticus. A (A6); B-C (A5); D-E (A7); F (A17). Câmara sub-estomática (cse); células buliformes (bul); epiderme adaxial (ad); epiderme abaxial (ab); esclerênquima (esc); espaço intercelular (esp); estômato (est); feixe vascular (fv); tricoma (tri). Barra: $A=100 \mu \mathrm{m} ; \mathrm{B}, \mathrm{E}=50 \mu \mathrm{m} ; \mathrm{C}, \mathrm{D}, \mathrm{F}=10 \mu \mathrm{m}$.

vitro, observaram que existe potencial para melhorar o valor nutritivo mediante seleção de plantas com rápidas taxas de digestão de parede celular. Nesse estudo, os autores verificaram elevada e negativa correlação $(\mathrm{r}=-0,76 ; \mathrm{P}<0,01)$ do conteúdo de lignina na parede celular com a digestão inicial da mesma. Buxton e Redfearn (1997) destacaram que uma pequena porção das células parece exercer um grande controle sobre a digestibilidade da fibra em plantas forrageiras e que em muitas dessas células a lamela média e a parede primária são provavelmente as responsáveis pela menor digestibilidade da fibra.

Os feixes vasculares mostram-se distribuídos no mesofilo em três tamanhos (Figura 1E-F). Os feixes de grande porte apresentam forma poligonal, estão envolvidos por endoderme e, mais internamente, exibem 
periciclo, com paredes lignificadas na face voltada para os tecidos vasculares. Essas observações estão de acordo com estudos anteriores em cevadilha vacariana, que destacaram a existência de dupla bainha ao redor dos feixes de grande porte (Gasser et al., 2002; Ramos et al., 2002). Nesses feixes há uma extensão de bainha lignificada que se projeta adaxial e abaxialmente.

A extensão da bainha do feixe apresenta-se mais lignificada na face abaxial (Figuras $1 \mathrm{C}$ e 2C). As espécies de braquiária estudadas por Brito e Rodella (2002) também evidenciaram a presença de uma extensão nos feixes maiores, assim como em grama-missioneira (Silva e Alquini, 2003). Os feixes de médio porte mostram bainha esclerenquimática em apenas uma das faces (Figura $1 \mathrm{~F}$ ), freqüentemente na face adaxial, porém, nas populações A6 e A8, quando os feixes estão na região dos sulcos, a extensão da bainha ocorre na face abaxial. Nos feixes de pequeno porte ocorre somente uma bainha parenquimática, às vezes com alguma célula de parede celular lignificada, o que também foi descrito por Ramos et al. (2002).

Gasser et al. (2002), em estudo comparativo de cevadilha vacariana e $S$. lachnea, indicaram a ausência da bainha Kranz na primeira, confirmando a existência da via fotossintética C3. Além disso, o número de células do parênquima existente entre os feixes vasculares na espécie analisada, é uma das características da folha com anatomia $\mathrm{C} 3$, a qual apresenta uma maior proporção de mesofilo em relação às plantas $\mathrm{C} 4$. Em geral, a bainha de feixe das espécies C3 é mais facilmente digerida comparada à bainha Kranz das $\mathrm{C} 4$, o que faz com que as primeiras sejam mais indicadas para alimentação animal (Gasser et al., 2002).

Pelo examinado neste trabalho, embora as folhas de cevadilha vacariana apresentem, visualmente, grande quantidade de esclerênquima, sua porção de parênquima é maior. Além disso, a espécie apresenta feixes vasculares de tamanho reduzido, o que diminui a quantidade de células do xilema, e, conseqüentemente, de tecidos lignificados. Tais informações ratificam seu valor como planta forrageira.

A variabilidade anatômica entre as populações, sumariadas na Tabela 1 , sugere diferenças na degradabilidade e digestibilidade da matéria seca e que pode ser explorada nos trabalhos de melhoramento genético.

TABELA 1: Características anatômicas de populações de Bromus auleticus.

\begin{tabular}{|c|c|c|c|c|c|c|c|c|}
\hline \multirow{2}{*}{ Estrutura } & \multicolumn{8}{|c|}{ População } \\
\hline & A5 & A6 & A7 & A8 & A17 & A23 & A26 & A27 \\
\hline Tricomas curtos & + & + & + & + & + & + & + & + \\
\hline Tricomas longos & - & + & - & - & - & + & - & + \\
\hline $\begin{array}{l}\text { Número de células } \\
\text { buliformes }\end{array}$ & $3-5$ & $3-5$ & $3-5$ & $3-5$ & $3-5$ & $3-5$ & $5-8$ & $3-5$ \\
\hline $\begin{array}{l}\text { Sulcos na superfí- } \\
\text { cie foliar }\end{array}$ & - & - & - & + & + & + & + & + \\
\hline $\begin{array}{l}\text { Clorênquima ho- } \\
\text { mogêneo }\end{array}$ & + & - & - & + & + & + & - & + \\
\hline $\begin{array}{l}\text { Clorênquima em } \\
\text { paliçada }\end{array}$ & - & + & + & - & - & - & + & - \\
\hline $\begin{array}{l}\text { Mesofilo com espa- } \\
\text { ços amplos }\end{array}$ & - & - & + & - & + & - & - & - \\
\hline
\end{tabular}

\section{Referências}

Alvarez, J. M.; Rocha, J. F.; Machado, S. R. 2005. Estrutura foliar de Loudetiopsis chrysothrix (Nees) Conert e Tristachya leiostachya Nees (Poaceae). Revista Brasileira de Botânica, 28: 23-37.

Barreto, I. L.; Kappel, A. 1967. Principais gramíneas e leguminosas das pastagens naturais do Rio Grande do Sul. Anais do $15^{\circ}$ Congresso Nacional de Botânica, Porto Alegre, Brasil, p.281-294.

Brito, C. J. F. A.; Rodella, R. A. A. 2002. Caracterização morfoanatômica da folha e do caule de Brachiaria brizantha (Hochst. ex A. Rich.) Stapf e B. humidicola (Rendle) Schweick. (Poaceae). Revista Brasileira de Botânica, 25: 221-228.

Buxton, D. R.; Redfearn, D. D. 1997. Plant limitations to fiber digestion and utilization. Proceedings of $37^{\circ}$ Annual Ruminant Nutrition Conference, Washington, USA, p.814-817.

Carlson, I. T.; Newell, L. C. 1985. Smooth bromegrass. In: Heath, M. E.; Barnes, R. F. \& Metcalfe, D. S. (eds). Forages. Iowa State University Press, Ames, USA, p.198-206.

Collins, M.; Drolsom, P. N. 1982. Composition and digestibility of smooth bromegrass clones selected for high and low IVDMD. Agronomy Journal, 7: 287-290.

Delgado, N. J.; Casler, M. D.; Grau, C. R.; Jung, H. G. 2002. Reactions of smooth bromegrass clones with divergent lignin or etherified ferulic acid concentration three fungal pathogens. Crop Science, 42: 1824-1831.

Ehlke, N. J.; Casler, M. D. 1985. Anatomical characteristics of smooth bromegrass clones selected for in vitro dry matter digestibility. Crop Science, 25: 513-517. 
Fahn, A. 1990. Plant anatomy. Pergamon Press, Oxford, UK, 588pp.

Ferdinandez, Y. S. N.; Coulman, B. E. 2001. Nutritive value of smooth bromegrass, meadow bromegrass and meadow $\mathrm{x}$ smoooth bromegrass hybrids for different plant parts and growth stages. Crop Science, 41: 473-478.

Gasser, M. M.; Ramos, J. C.; Tivano, J. C.; Vegetti, A. C. 2002. Anatomia foliar de Bromus auleticus y Setaria lachnea sometidas a digestión in situ. Revista de la Facultad de Agronomia, 105: 68-76.

Hacker, J. B. 1981. Selection and breeding better quality grasses. In: Hacker, J. B. (ed.) Nutritional limits to animal production from pastures. CAB, Farnham Royal, UK, p.305-323.

Johansen, D. A. 1940. Plant Microtechnique. Mc Graw Hill, New York, USA, 503pp.

Longhi-Wagner, H. M. 1987. Flora ilustrada do Rio Grande do Sul - Gramineae - Tribo Poeae. Boletim do Instituto de Biociências, 41: 1-191.

Luque, R.; Souza, H. C.; Kraus, J. E. 1996. Métodos de coloração de Roeses (1972) modificado e Kropp (1972) visando a substituição do azul de astra por azul de alcião 8 GS ou 8 GX. Acta Botanica Brasilica, 10: 199-212.

Mauseth, J. D. 1988. Plant anatomy. The Benjamin Cummings, California, USA, 560pp.

Millot, J. C. 2001. Bromus auleticus: uma nueva espécie domesticada. In: PROCISUR (ed.). Los recursos fitogenéticos del género Bromus en el Cono Sur. Procisur, Montevideo, Uruguay, p.3-6. (Diálogo, 56).

Moreno, J. A. 1961. Clima do Rio Grande do Sul. Secretaria da Agricultura, Porto Alegre, Brasil, 41pp.
Oliveira, J. C. P.; Moraes, C. O. 1993. Distribuição da produção e qualidade de forragem de Bromus auleticus Trinius. Pesquisa Agropecuária Brasileira, 28: 391-398.

Oliveira, J. C. P.; Silveira, L. R. M.; Moraes, C. O. M.; Sarmento, M. B. 2001. Determinação do modo de reprodução de Bromus auleticus Trinius ex Nees (Poaceae): estudio mediante isoenzimas. Agrociência, 5: 32-40.

Paciullo, D. S. C. 2002. Características anatômicas relacionadas ao valor nutritivo de gramíneas forrageiras. Revista Ciência Rural, 32: 357-364.

Ramos, J. C.; Tivano, J. C.; Vegetti, A. C. 2002. Estudio anatómico de vástagos reproductivos en Bromus auleticus Trin. ex Nees (POACEAE). Gayana Botánica, 59: 51-60.

Scheffer-Basso, S. M.; Xavier, C. A.; Flores, J. D.; Dall'Agnol, M.; Favero, D. 2005. Variabilidade morfofisiológica e agronômica em populações de Bromus auleticus (Cevadilha vacariana). Biociências, 13: 3-10.

Silva, L. M.; Alquini, Y. 2003. Anatomia comparativa de folhas e caules de Axonopus scoparius (Flügge) Kuhlm. e Axonopus fissifolius (Raddi) Kuhlm. (Poaceae). Revista Brasileira de Botânica, 26: 185-192.

Silveira, L. R. M.; Oliveira, J. C. P.; Moraes, C. O. 1997. Análise da diversidade genética em acessos de Bromus auleticus. Revista Ciência Rural, 27: 381-385.

Traverso, J. E. 2001. Colecta, conservación y utilización de recursos geneticos de interés forrajero nativo y naturalizado: Bromus auleticus, Trin. ex Nees (Cebadilla chaqueña). In: PROCISUR (ed.). Los recursos fitogeneticos del género Bromus en el Cono Sur. Procisur, Montevideo, Uruguay, p.7-18. (Diálogo, 56) 